\title{
A FORMAÇÃO CONTINUADA - ESPECIALIZAÇÃO EM EDUCAÇÃO DO CAMPO E SUA RESPONSABILIDADE SOCIAL
}

\section{A CONTINUING EDUCATION - EDUCATION OF EXPERTISE IN THE FIELD AND ITS SOCIAL RESPONSIBILITY}

Maurício Cesar Vitória Fagundes ${ }^{1}$ Silvana Cassia Hoeller ${ }^{2}$

\section{RESUMO}

A responsabilidade social é uma demanda que poderá ser atingida quando as universidades problematizarem a sua relação com a sociedade. O questionamento só será possível quando houver espaços para a reinvenção da realidade. Nesse contexto a universidade pode representar uma condição de Projeto que avança na direção de novos paradigmas. A sociedade vem reconhecendo a existência de outros espaços de produção do conhecimento e colocando em questão as tradicionais funções da universidade. Assim, o artigo traz as experiências construídas a partir da UFPR Litoral que tem como premissa sua responsabilidade social e firma posição pautando-se em princípios democráticos e emancipatórios, explicitados pelo compromisso da universidade pública. Esse processo pode ser sentido nos cursos de pós-graduação em Educação do Campo, que faz o exercício de pensar o conhecimento a partir da realidade concreta de seus sujeitos.

Palavras-chave: Emancipatório - Conhecimento - Educação do campo

\begin{abstract}
Social responsibility is a demand can only be achieved when universities problematize their relationship with society. The question is only possible when there is space for the reinvention of reality. In this context the university can be acondition of projest that advances towards new paradigms. The company has recognized the existence of others Spaces of knowledge new paradigms. The company has recognized the existence of other spaces of knowledge production and putting into question the traditional university functions. Thus, article experiences built back from the coast UFPR that is premised on its social responsibility and firm position basin on principles of democracy andemancipation, as specified by the commitment of the public university. This process can be felt in their post-graduate course in rural education, which makes the exercise of thinking about knowledge from the reality of the subject.
\end{abstract}

Key words: Emancipatory; Knowledge; Education Field

\section{A Formação Continuada - Especialização em Educação do Campo e sua responsabilidade social}

Na década de 60, Vieira Pinto (1994) escreveu a obra intitulada “A Questão da Universidade", onde problematizou a relação entre universidade e sociedade e a necessária responsabilidade e compromisso social que o ensino superior deveria assumir com os interesses da população trabalhadora. Saviani (In VIEIRA PINTO, 1994), ao apresentar essa obra, enfatizou

1 Professor doutor em Educação da UFPR - Setor Litoral, mauriciovitoriafagundes@gmail.com

2 Professora da UFPR - Setor Litoral - área de agroecologia, silvanano@ufpr.br 
a importância de situá-la e datá-la, pois fora concebida e escriturada "no bojo do processo que então se caracterizava como pré-revolucionário. [...] A sociedade tendia a se polarizar entre os que se colocavam a favor do objetivo revolucionário [...] e aqueles que se colocavam contra" (p. 5); esses últimos procuravam "preservar a ordem vigente e se utilizando de todos os recursos disponíveis para frustrar os intentos transformadores" (id. ibid. p. 5).

Vieira Pinto (1994) percebia a universidade brasileira como "uma peça de domínio pelo qual a classe dominante exercia o controle social, particularmente no terreno ideológico, sobre a totalidade do país" (p. 19). Diante dessa percepção, o autor defendia a urgência de uma reforma de caráter político e não meramente pedagógico, embora entendesse que este último também fosse necessário, porém após ser definido o projeto político e sua participação com a comunidade na transformação social do país.

Para o autor, centrar o atraso e a deficiência da universidade na estrutura e no funcionamento didático conduz a um grave equívoco e resultados desastrosos. Nesse sentido a discussão permaneceria intra-universidade, sendo avaliada apenas a melhor forma de organizar o ensino para os alunos que entraram na universidade. "Ora, aqui está o vício radical desta atitude: não indagar por que esses alunos entraram para a universidade, e por que milhões de outros não entraram" (id. ibid. p. 20). O autor propõe colocar a universidade em discussão no âmbito da sociedade brasileira, para definir seu papel social e a partir dele, discutir os aspectos internos como organização didática, jurídica, ética, econômica, etc.

No Brasil, essa nova síntese histórica força um processo regulatório com distintas normas legais para a política e para a educação, materializadas, respectivamente, em uma nova Constituição Federal promulgada em 1988 e uma nova Lei de Diretrizes e Bases da Educação Nacional - LDBEN - 9394/96. A LDB introduziu possibilidades de uma ampliação da oferta do ensino superior sem o necessário acompanhamento da pesquisa e extensão, que ficariam afeitas às universidades; instituiu a avaliação dos cursos de graduação e das instituições e estabeleceu um número mínimo de mestres e doutores no corpo docente das IES, na expectativa de garantir uma melhor qualidade do corpo docente.

Essa Lei criada dentro de um contexto global refletiu um grande interesse pela melhor qualificação da mão-de-obra e sua expansão quantitativa. Esse fato pode ser observado pela flexibilização que favoreceu a criação de estabelecimentos privados de ensino superior; pelas políticas públicas de ampliação de vagas e a intensificação dos cursos de curta duração para formação tecnológica. Esses impactos sobre o ensino superior, em termos globais e com forte repercussão local, foram decorrentes do neoliberalismo ${ }^{3}$.

3 Doutrina desenvolvida a partir da década de 1970, que defende a absoluta liberdade de mercado e a restrição da intervenção estatal sobre a economia, admitida apenas em setores imprescindíveis, ainda assim, no menor grau possível. 
Entretanto, a condição dialética que caracteriza os movimentos civilizatórios reafirma as resistências e anuncia a possibilidade de novas construções. O novo século trouxe consigo a esperança de que é necessário e possível garantir espaços para a reinvenção da realidade. Nesse contexto a universidade pode representar uma condição de Projeto que avança na direção de novos paradigmas. A sociedade vem reconhecendo a existência de outros espaços de produção do conhecimento e colocando em questão as tradicionais funções da universidade.

Nessa senda, em 2005 foi criado o Setor Litoral da UFPR. Sua proposição explícita e literal de seu Projeto Político-Pedagógico é de superar os pressupostos da modernidade e lançar-se na construção de um projeto inovador e emancipatório. Ou seja, faz um rompimento paradigmático ao optar por instalar-se em uma região com fortes índices de pobreza, revelados pelos indicadores econômico-sociais.

Desse modo, a UFPR Litoral tem como premissa primeira sua responsabilidade social e firma posição pautando-se em princípios democráticos e emancipatórios, explicitados pelo compromisso da universidade pública com os interesses coletivos; a indissociabilidade entre ensino, pesquisa e extensão; e, a formação de um aluno crítico, criativo, capaz de transformar a realidade.

O movimento subsequente a apreensão da realidade das comunidades teve data para iniciar, mas não tem data para acabar, foi revelando e constituindo Cursos que fossem significativos nas relações com a comunidade. Portanto, toma como princípio a reflexão acerca da realidade concreta do lugar, como fonte primeira, para o diálogo com o conhecimento sistematizado, tecendo a organização curricular e o desenvolvimento de projetos que partem dos alunos e envolvem os professores e a comunidade.

Nessa compreensão a UFPR Litoral insere-se na realidade regional do litoral paranaense e Vale do Ribeira, para desenvolver, juntamente com essas comunidades, um projeto que tem como pressuposto a ação coletiva e a ação de protagonismo de seus sujeitos, que integre a educação pública em todos os seus níveis, desde a educação infantil até a pós-graduação.

Nesse contexto e na mesma perspectiva epistemológica inserem-se os cursos de formação de professores, as pós-graduações, como a Especialização em Educação do Campo, que faz parte de um Programa Federal denominado Saberes da Terra.

O Programa Saberes da Terra tem como um dos principais diferenciais o respeito às especificidades e a identidade dos povos do campo por meio de um processo educacional diferenciado. Tem como desafio vincular a prática pedagógica ao trabalho no campo, além de projetar outras formas de diversificação na propriedade, que potencializem o desenvolvimento de um projeto de vida na perspectiva de sustentabilidade, humana, ambiental e econômica. 
O campo retrata uma diversidade sociocultural que se dá a partir dos sujeitos que nele habitam: assalariados rurais temporários, posseiros, meeiros, arrendatários, acampados, assentados, reassentados atingidos por barragens, agricultores familiares, vileiros rurais, povos da floresta, indígenas, descendentes negros provenientes de quilombos, pescadores, ribeirinhos, e outros mais. O campo é bastante heterogêneo, agregando sujeitos de diferentes gerações, etnias, gêneros, crenças e com distintas experiências de trabalho, de organização e modo de vida.

Os educadores/as e a equipe pedagógica que trabalham nas escolas do campo, muitas vezes, desconhecem o contexto, a história, a cultura do campo e de seus povos. O modelo de currículo, historicamente adotado, em geral, é baseado na cultura urbana e nos saberes produzidos nesses espaços.

Esse curso de Especialização em Educação do Campo coloca-se como fundamental para possibilitar aos professores que trabalham com os sujeitos do campo e que fazem parte da rede pública de ensino, a possibilidade de conhecer, refletir sobre as práticas em sala de aula, a partir da história e a cultura camponesa sobre a luz das Diretrizes Nacionais para a Educação do Campo.

A Resolução CNE/CEB 1, de 3 de abril de 2002 institui as Diretrizes Operacionais para a Educação Básica nas Escolas do Campo trazendo um de orientações para serem assumidas pelos órgãos públicos, as universidades e pelas próprias escolas. Nestas, a identidade da escola deve ser definida a partir dos seus sujeitos e da realidade em que se insere. No artigo $2^{\circ}$, $\S$ único, das Diretrizes da Educação do Campo, afirma-se que

\begin{abstract}
A identidade da escola do campo é definida pela sua vinculação às questões inerentes à sua realidade, ancorando-se na temporalidade e saberes próprios dos estudantes, na memória coletiva que sinaliza futuros, na rede de ciência e tecnologia disponível na sociedade e nos movimentos sociais em defesa de projetos que associem as soluções exigidas por essas questões a realidade social da vida coletiva no país.
\end{abstract}

A Resolução CNE/CEB 1, de 3 de abril de 2002 que institui as Diretrizes Operacionais para a Educação Básica nas Escolas do Campo destaca a necessidade de formação inicial e continuada, habilitando todos os professores leigos e promovendo o aperfeiçoamento permanente dos docentes atuantes nas escolas do campo. Partindo de diversas experiências dos movimentos sociais na formação de educadores, Miguel Arroyo ${ }^{4}$ levanta alguns elementos para a formulação de políticas de formação de profissionais que atuam nas escolas do campo. Seu texto traz ainda elementos para a pesquisa e, sobretudo, para propostas de currículos dos cursos de formação, de modo a cumprirem com sua responsabilidade de formar educadoras e educadores para garantir o direito à educação dos povos do campo.

[...] a especificidade na formação de educadoras e educadores do campo não é mais para ser questionada, mas garantida. Vai se consolidando a consciência de que os

4 ARROYO, Miguel Gonzalez. Políticas de formação de educadores (as) do campo. Cad. Cedes, Campinas, vol. 27, n. 72, p. 157-176, maio/ ago. 2007. 
direitos carregam as especificidades de seus sujeitos concretos, dos coletivos sociais históricos que são titulares desses direitos.

O autor destaca que os movimentos sociais e o coletivo de educadores do campo consolidam a ideia de que a formação específica para o educador (a) do campo deva incluir o conhecimento do campo, as questões relativas ao equacionamento da terra ao longo de nossa história, as tensões no campo entre o latifúndio, a monocultura, o agronegócio e a agricultura familiar; conhecer os problemas da reforma agrária, a expulsão da terra, os movimentos de luta pela terra e pela agricultura camponesa, pelos territórios dos quilombos e dos povos indígenas. Conhecer a centralidade da terra e do território na produção da vida, da cultura, das identidades, da tradição, dos conhecimentos. Destaca também a necessidade de um conhecimento das formas específicas de exercer o ofício de ensinar, educar no campo. Identificar as formas de exercer o magistério e a educação nas escolas de educação da infância, na educação fundamental e média e na EJA no campo. Modelos de formação de professores que extrapolem a estreita formação por disciplinas e avança para a formação por áreas e, se possível, em mais de uma área do conhecimento.

Neste sentido, a UFPR Litoral também se encontra engajada no desafio colocado aos alunos e professores das universidades de construírem currículos e cursos que apresentem concepções de formação e de educação do campo. A proposta abrange uma organização curricular e processos de aprendizagem que visam respeitar às características e as realidades da vida dos povos do campo, reforçando a necessidade de implantação de políticas públicas que atendam as demandas do campo paranaense, em especial da sua juventude e da formação continuada de seus educadores.

Considerando que a educação do campo não se resume à escola, as Diretrizes Operacionais incentivam a construção de Projetos Institucionais das escolas do campo que possibilitem ser a "expressão do trabalho compartilhado" e constituindo-se num "espaço público de investigação e articulação de experiências e estudos direcionados para o mundo do trabalho", a fim de se buscar um "desenvolvimento social, economicamente justo e ecologicamente sustentável" das práticas sociais dos povos do campo (Art. $4^{\circ}$ ). Como se vê, a Educação do Campo compreende que os sujeitos têm história, participam de lutas sociais, têm nome e rostos, gêneros, raças, etnias e gerações diferenciadas. O que significa que um projeto de educação do campo leva em conta as pessoas e os conhecimentos que estas possuem.

Dois aspectos precisam ser considerados na Educação do Campo: o primeiro, diz respeito à superação da dicotomia entre rural e urbano e o segundo, à necessidade de recriar os vínculos de pertença dos sujeitos ao campo. Esses dois aspectos somados à diversidade dos povos do campo exigem um processo educativo que afirme a educação como um processo ao longo 
da vida. Compreender o campo e a educação do campo como um espaço socialmente integrado ao mundo rural e urbano, superando a dicotomia entre esses dois espaços sociais, resulta na promoção de uma identidade coletiva que fortalece a criação de parcerias entre os diversos segmentos sociais, visando a criação de políticas públicas por meio de novas experiências de escolarização e de inovação no processo educacional.

O curso de Formação Continuada se fundamenta nesses marcos operacionais da Educação do Campo e propõe a construção de um projeto educativo que deva tratar os cidadãos campesinos como sujeitos das suas produções, utilizando os seus recursos naturais de modo sustentável na produção de sua própria existência.

Entende-se que a educação oculta um papel político na construção dos modelos de desenvolvimento, sendo ambos fundamentais para a construção de outro modelo de desenvolvimento, sob bases sustentáveis e includentes na construção de um projeto contra hegemônico. Este papel político é central nas discussões sobre a educação do campo. Apesar do rural já ter sido alvo das políticas públicas e em especial das políticas públicas de educação, o que esteve historicamente por trás deste ensino foi a implementação de um modelo de desenvolvimento que visa à modernização agrícola das grandes propriedades ou o desenvolvimento urbano e industrial.

A proposta da Educação do Campo encontra-se atrelada a outro projeto de desenvolvimento: econômico, social e sustentável. Nesta perspectiva, desenvolvimento não é sinônimo de crescimento econômico, mas um conceito complexo: ampliam-se os seus adjetivos: sociais, econômicos, políticos, culturais, ambientais, sustentáveis etc. Na análise sobre o desenvolvimento é importante retomar a ideia de Ignacy Sachs (2004) p. 13.

O desenvolvimento, distinto do crescimento econômico, cumpre esse requisito (de interligar economia e ética), na medida em que os objetivos do desenvolvimento vão bem além da mera multiplicação de riqueza material. O crescimento é uma condição necessária, mas de forma alguma suficiente (muito menos é um objetivo em si mesmo), para se alcançar a meta de uma vida melhor, mais feliz e mais completa para todos.

Igualdade, equidade e solidariedade estão embutidas no conceito de desenvolvimento. Amartya Sen no livro Desenvolvimento como liberdade relaciona a questão do desenvolvimento e da justiça não apenas ao acesso aos bens materiais ou a uma ampliação das rendas, mas também a ampliação da capacidade de escolha das pessoas, como por ex. de permanecer ou não no meio rural.

A proposta de Formação Continuada de educadores e coordenadores de turma do ProJovem Campo referencia o desenvolvimento sustentável do campo em âmbito local e regional com base na Agroecologia, além de englobar propostas metodológicas de planejamento, execução e avaliação do processo pedagógico por meio da pesquisa-ação-reflexão; e de caráter 
político-pedagógico: intencionalidade de educação do campo a favor da construção de uma nova concepção de campo, de reforma agrária e de agricultura familiar, e o papel do educador neste processo.

O curso de especialização baseia-se na proposta de Paulo Freire de resgate do humano como sujeito de si e de sua própria educação. O pensador argumenta em defesa da educação, como dinamizadora do processo de mudança, firmando as bases da aprendizagem: Capacidade de autorreflexão como desenvolvimento da consciência crítica, que reorganiza as experiências vividas, transformando a realidade; A aprendizagem modifica o homem que, ao mesmo tempo em que se renova, mantém a própria identidade. Portanto, uma aprendizagem libertadora de conquista e aumento de autonomia; A busca permanente como sujeito, e não objeto da educação; com a consciência da característica humana de ser inacabado; A noção de tempo, que diferencia homens de animais, e caracteriza o homem como ser histórico, capaz de construir o futuro com base no passado.

O curso pressupõe como princípio a educação libertadora - progressista, pois os envolvidos nos cursos são sujeitos construtores da história e transformadores do mundo. Assim, a especialização possibilita a formação continuada de educadores/as ligados ao campo, mas também se apresenta como um espaço de diálogo entre a Educação de Jovens e Adultos (EJA) e a reflexão que os educadores fazem de sua práxis em sala de aula.

Isso possibilita também que a Universidade tenha um espaço construído e pensado a partir das comunidades do campo em conjunto com a educação pública do ensino básico.

Por fim, entendemos que refletir sobre a possibilidade de outro tipo de formação é desejável e necessário, e se institui como possibilidade concreta e possível quando identificamos teoria e prática, numa unidade dialética, no sentido de "construir sobre uma determinada prática uma teoria, a qual coincidindo e identificando-se com os elementos decisivos da própria prática, acelere o processo histórico em ato, tornando a prática mais homogênea, coerente, eficiente" [...] (GRAMSCI, 1989, p. 51). O autor enfatiza que o problema da identidade de teoria e prática estabelece a possibilidade da "transição", isto é, de aceleração da transformação. Nessa perspectiva de identidade, os movimentos podem ser desencadeados tanto pelas forças práticas ou pela multiplicação dos programas teóricos demandados pela "justificação realista”, ou seja, da realidade concreta, de acordo com sua possibilidade de assimilação pelos movimentos práticos.

Em assim sendo, o PPP da UFPR Litoral, a formação Continuada e os Cursos de Especialização em Educação do Campo, podem ser elementos que aglutinam, em espaço micro, as relações ("práticas") desenvolvidas na sociedade, tornam-se instrumento rico do pensar ("teoria") e do agir ("processo histórico em ato") docente/discente/comunidade, tanto para sua 
reprodução como para sua superação.

Com tais ações (práticas) e concepções epistemológicas que fundam e sustentam o pensar sobre a prática (teoria), vislumbramos a possibilidade de construção de alternativas, justas, do ponto de vista social, cultural, ambiental, ou seja, de desenvolvimento sustentável.

\section{Referências}

ARROYO, Miguel Gonzalez. Por um tratamento público da educação do campo. Por Uma Educação do Campo, Brasília, n. 5, p. 91-108, 2004.

BRASIL. Congresso Nacional. Lei de Diretrizes e Bases da Educação Nacional no 9394/96. . Congresso Nacional. Plano Nacional de Educação. Lei no ${ }^{\mathbf{1 0}}$ 172/2001. . Congresso Nacional. Decreto $\mathbf{n}^{0}$ 5154/2004.

. Conselho Nacional de Educação/Câmara de Educação Básica. Diretrizes Curriculares Nacionais para a Educação de Jovens e Adultos. Parecer no 11 aprovado em 10 de maio de 2000.

Conselho Nacional de Educação/Câmara de Educação Básica. Diretrizes operacionais para a educação básica nas escolas do campo. Resolução n 1 de 03 de abril de 2002.

. Ministério da Educação. Referências para uma política nacional de educação do campo: caderno de subsídios. (2004).BUARQUE, Cristovam. A aventura da universidade. São Paulo: Editora da Universidade Estadual Paulista; Rio de Janeiro: Paz e Terra, 1994.

FAGUNDES, Maurício Cesar Vitória. UNIVERSIDADE E PROJETO POLÍTICO-PEDAGÓGICO: diálogos possíveis fomentando formações emancipatórias. 235 f. Tese de Doutorado em Educação. Programa de Pós-Graduação em Educação. Universidade do Vale do Rio dos Sinos, [2009].

FREIRE, Paulo. Pedagogia da autonomia. Saberes necessários à prática educativa. 4. ed. São Paulo: Paz e Terra, 1996.

GRAMSCI, Antonio. Concepção dialética da história. 8 ed. Rio de Janeiro, RJ: Civilização Brasileira, 1989.

SACHS, Ignacy. Desenvolvimento: includente, sustentável e sustentável e sustentado. Rio de Janeiro: Garamond, 2004.

SEN, Amartya. Desenvolvimento como Liberdade. São Paulo: Companhia das Letras, 2000.

SOUSA SANTOS, Boaventura. Pela mão de Alice: o social e o político na pós-modernidade. 7. Ed. São Paulo: Cortez, 2000.

VIEIRA PINTO, Álvaro. A questão da Universidade. 2. Ed. São Paulo: Cortez, 1994. 